\title{
Negotiating the Culture of the Academy: Chinese Graduate Students in Canada
}

\author{
Sheila Windle (University of Windsor) \\ Bev Hamilton (University of Windsor) \\ Min Zeng (University of Windsor) \\ Xiaodong Yang (University of Alberta)
}

\begin{abstract}
This paper presents the process and results of a narrative inquiry into the stories of eight Chinese international graduate students. Results show three main commonalities in participants' education narratives in China: parental influence, the exam system and independent study. In the Canadian setting, specific aspects of the academic culture are experienced as permeable (written work, lab work, tests and reading ability) or impermeable (in-class discussions, oral presentations, group work, oral discourse, communicating with local people). Discussion articulates participants' use of unique personal resources, which results in distinctive trajectories of entry into and navigation within this new academic culture.

\section{Résumé}

Cet article présente le processus et les résultats d'une enquête narrative de huit étudiants internationaux chinois de troisème cycle. Les résultats montrent les trois éléments communs dans la narration des participants: l'influence des parents, le système des examens, et l'étude individuelle. Dans le cadre canadien, les participants ont reconnu des aspects spécifiques de la culture académique comme perméables (travaux écrits, travaux de laboratoire,les examens et compétence en lecture) ou imperméables (discussions en classe, présentations orales, travaux en groupes, entretiens oraux, et communication avec les habitants locaux). La discussion clarifie l'usage d'uniques ressources personnelles par chaque participant La discussion clarifie l'usage d'uniques ressources personnelles par chaque participant dont le résultat définit des trajectoires distinctifs d'entrée et de navigation au cœur de cette nouvelle culture académique.
\end{abstract}

The authors wish to acknowledge the direction and support of Dr. Nombuso Dlamini throughout this research initiative.

\section{Introduction}

When students embark on a graduate program, they must come to terms with the specific values, hierarchies, discourses and requirements of its academic culture (Tanaka, 2002). This interpretive community can be an arena of aspiration and achievement or it can provide opportunities for negotiating or resisting that which is being discovered and experienced (Bartolomae, 1986). Through participating in this complex process of learning the academic culture, outsiders can be 
transformed into full participants in the production of knowledge within the culture (Welch, 1993; Williams \& Garcia, 2005). At the same time, alternative narratives of cynicism, failure, silencing, and alienation may also come to be constructed through this process.

For international students, the processes of learning the discourses of the academy are more complex. The process of "entering" the academic culture requires the understanding of intricate interaction patterns, the acceptance of foreign goals and roles, and the performance of a number of culturally constructed practices and rituals. It also requires the perception and interpretation of implicit and unconscious cues, the recognition of the ways in which resistance and negotiation can most effectively take place, and the ways in which intellectual capital can be gathered, recognized and circulated within such a culture (Fairclough, 1993, 1995; Gee, 1999, 2005).

In this paper, we examine the narratives of Chinese graduate students at a Canadian university to form an understanding of their personal knowledge of the academy, their social identities, and how these were instrumental in the process through which they came to understand and work within a new academic culture. We pose the following questions: How do these Chinese graduate students experience the academic culture of the Canadian university? How do their social and cultural identities enhance or limit full participation in this academic culture? That is, how do they, as people coming from countries that are culturally different from Canada, shape their participation in the academy? We focus primarily on the academic experience of students, rather than their participation in the wider culture as a whole, bearing in mind that any aspect of our experience cannot be completely separated from the rest.

\section{Theoretical Framework}

Typically, studies of international students have tended to focus on their frustration, alienation, and difficulty situating themselves effectively within the academic environment because of cultural, philosophical, and linguistic differences (Cooke, 1995; Dee \& Henkin, 1999; Erwin \& Coleman, 1998; Feiz, 1995; Grayson \& Stowe, 2005; Kilbride \& D’Arcangelo, 2002; Ku, Lee, Pan, Tao, Wang, Cornell \& Ku, 2001; Sheh, 1994). Success is typically associated with assimilation and is most often determined by students' ratings on Likert-type scales constructed by Western researchers (Tanaka, 2002). While these studies provide valuable information, they do not offer a holistic representation of students' experiences, but rather, their perceived level of ease or difficulty within pre-determined categories of adaptation. As such, it is not clear that the experiences of international graduate students as narrated by the academic community represent the insiders' views of their experiences. Further, while systemic racism and cultural barriers experienced by students from minority 
cultures have been shown to play a significant role in their struggle to participate in academic institutions (Razack, 1995; Solomon, 1997; Solomon \& LevineRasky, 2003), the positioning of international graduate students as marginalized and diminished victims of cultural barriers cannot be accepted uncritically. The narrative of entry into academic culture must include international students' own perceptions of their ultimate goals and academic culture, and their own understanding of aspiration, resistance, negotiation and collaboration within the intersecting cultures. The methodology of this study was carefully planned to facilitate elucidation of Chinese graduate students’ perspectives.

\section{Methodology}

Research Team Composition

This study was conducted by two Chinese-born and two Canadian-born graduate students, and was informed by Solomon and Levine-Rasky's (2003) work with cross-cultural dyads in a teacher education program. The use of cross-cultural dyads provides a structure for individuals of different cultural backgrounds to develop productive work relationships and tackle sensitive racial and cultural issues (Solomon, 1998). In this case, our cross-cultural research team afforded us access to the frameworks of both Canadian and Chinese academic cultures, and allowed us to explore divergent perspectives arising from our historically contingent cultural identities.

\section{Narrative Inquiry}

In narrative research, inquirers collect and tell stories about people's lives, write narratives of individual experiences and discuss the meaning of those experiences, analyzing the story for chronological information about individuals' past, present and future (Creswell, 2003). Narratives reflect "a kind of life story" which enables us to study "how humans make meaning of experience by endlessly telling and retelling stories about themselves" (Connelly \& Clandinin, 1990, p. 14). The word "story" is used interchangeably with "narrative" throughout this study. With narrative inquiry as our guiding approach to data collection, we followed the following stages: positioning, participant selection, and interviews.

\section{Positioning}

Before contacting any participants, each research team member wrote an autobiographical reflection of her or his life experiences with respect to education. This process assisted us in clarifying cultural and personal differences that might affect data gathering and interpretation, and in understanding one another as individuals and as a unified team, examining, literally "where we were coming from.” 


\section{Participant Selection}

Selection of participants was purposive (Ristock \& Pennell, 1996) in that researchers sought international students with a range of academic experiences based on self-report of grades, involvement in the professional practices of the academy, and their sense of integration into their respective departments. Participant selection was informed by peer associations of the Chinese researchers within the university's Chinese international students' community. The final sample included four females and four males.

\section{Data Collection: Interviews}

In-depth interviews were conducted by cross-cultural dyads (one Chinese researcher and one Canadian researcher). Each dyad conducted four interviews with individual participants. In addition to the advantages outlined by Solomon and Levine-Rasky (2003), it was advantageous to have one Chinese researcher in the interviews, so that participants could speak in either English or Mandarin. Interviews lasted between one and two-and-a-half hours, and were recorded on audiotape. The Chinese researchers translated the few Mandarin components of interview data into English.

\section{Data Analysis: Critical Discourse Analysis}

Critical Discourse Analysis (CDA) (Fairclough, 1993, 1995; Fairclough \& Wodak, 1997) attempts to identify the connections between discourse practices, social practices and social structures. CDA provides a framework to integrate three separate forms of analysis: spoken or written language texts, discourse practices (production, distribution and consumption of texts) and discursive events as instances of sociocultural practices (Fairclough, 1995). This analytical method provides a working framework for discussing the way that discourses, both those of the participants and those of the researcher, shape and are shaped by, culture. In the present study, we employed CDA to analyze the interview data, following the three-step process outlined by McGregor (2002). Two Chinese researchers and two Canadian researchers teamed up into monocultural dyads to conduct the CDA and then all four researchers met to discuss the meanings they had constructed from interview data based on the CDA process.

\section{Results}

This section will discuss commonalities in participants' narratives of their educational experiences in China and Canada. Then, participants' positioning of themselves as insiders or outsiders will be discussed. In their narratives of academic experiences in China, strong parental influence (Tsai, 2006), the exam system and independent work were most common. In the Canadian setting, 
language problems, assuming personal responsibility for difficulties, and dominant social influences were the common threads.

\section{Academic Narratives in China \\ Parental Influence}

Parental influence was prominent in participants' narratives, for example, in emphasizing the importance of education, how to study, how much to study, choice of university, choice of career path, and the decision to attend graduate school overseas. Zhou, when asked why she decided to go to graduate school, responded, "Two things. One is my father, he asked me to do, the other is my working experience after university" (Zhou). Similarly, Yang chose engineering because her father, brother and sister were engineers . The parental pressure began in elementary school. According to Dong, "The only thing I remember in primary school - that - the final exam ... I screwed it and I think my father was very very angry at that. My - my father said, 'You might screw your whole life.' ... So I started to work hard."

Many stories recounted intense surveillance from both parents and teachers, with pressure to focus solely on academic success as the route to successful employment. One student, Jiang, described her experiences in the following way: "My mom is always telling me, you shouldn't go to sleep at this time. You see that girl [who lives nearby], her light is on, you should concentrate on your study."

There was a common belief that education was essential to having a "bright future." Huang pointed out her early ambition of getting into the top, "key" classes.

I must...go to key class, in the high school, or if cannot you know the situation in China. If you cannot go to the key class, and maybe you cannot go to school or university. If you cannot go to a good university, you cannot find a good job, and then, so on. So, if you cannot find a good job, then you do not have a bright future. So I must study hard.

Zhang shared what he had learned from his most influential teacher in China: "If you work hard, you will get a real future." In Yang's case, "If I can't enter a university, I can't find a decent job so all children in China perhaps do that." Evidence of the fundamental value of education came from Song's transcript. In essence, Song's perception was that without a university education, she was worthless. "In China if you don't go to university that means that you are nothing. Our purpose of study is going to university ... and your parents will be happy to show you off to your friends." A university education would make her parents proud, something very important to Song. In addition to strong parental 
involvement, the exam system resurfaced regularly in participants' academic lives in China.

\section{Exam System}

Participants acknowledged that the Chinese exam system exerted a powerful influence in their lives, shaping to different degrees their work practices, their views of what constituted legitimate knowledge, and the valuing of their own learning. As Dong said, "the exam is the only good way to force you to study hard.” Exams, in a sense, defined what was important, that is, what was and was not necessary to remember. As another participant, Zhang said, "exams always give me idea, what should I learn and what I shouldn't learn.”

When probed about their perceptions of and experiences with the exam system, most participants gave negative descriptors ranging from dull and boring to torturous and nightmarish. According to Huang, “Almost every student hates hates - exams.” Jiang stated,

There's an exam before the entrance for university, so at that time there's nightmare for most of the students, and everyday from 7 o'clock to 9 o'clock in the evening, we stay at school actually, and we pay for our meals, and for any other time we have no break at all.

Zhou's experience in the last year of high school was identical. "A lot of exams and a lot of homework, we don't have time to do other things. Even we have to study late at night, because it's very hard to get into university” (p. 1). Song thought the university entrance exam was unfair because a student may have done very well for three years of high school, but if she or he performs poorly on the three days of examination, her or his entire future would be negatively and irrevocably affected. "That exam is very strict. And if you did a good job in exam you go to great university but if you fail you enter a worst university but I think it's unfair” (Song).

Participants expressed great relief in knowing that they were finished with high school exams and the university entrance exam in particular. With respect to how they studied, most study was independent and silent as explained in the next section.

\section{Independent Study}

A third theme in China was independence, that is, relying only on one's self for study. Here, Jiang outlines the general rules for studying.

First of all you must have higher scores and you must depend on yourself very well. Don't talk to other students when the time is for self study, and if you discuss some questions with others, you are putting yourself into trouble.

Analysis of this excerpt reveals more than the importance of working independently. The system is the unquestioned authority; therefore students 
"must" do many things. Further, "Don't talk to other students" is an imperative that echoes the authoritative voice of teachers in China. The use of "higher" rather than "high" suggests the competitive nature of education in China, and the final phrase of this corpus places responsibility squarely on students' shoulders, i.e., if you get into trouble, you (and not the teacher) are "putting yourself" there.

Zhou contrasted the independent aspect of education in China with her experiences in Canada:

In China, in one course, you can do everything by yourself, here no. I take one undergraduate course, three people form a group, you must know communicate with other people to do the job. In China I always do project myself, I don't need to communicate with other people, here no.

Other participants mentioned independent study when they spoke of their educational experiences in Canada, observing, like Zhou, that this was different because they were more accustomed to working independently rather than in groups. When asked whether group work in Canada was similar to that in China, Ming responded, “I don't know. I didn't have any group project.” In fact, most participants mentioned group work as an area in which they experienced challenges in their graduate life in Canada. The next section outlines themes that emerged from participants' experiences as graduate students in Canada.

\section{Academic Narratives in Canada \\ Language}

The most common theme in participants' narratives in Canada was the English language. This was the most difficult challenge they faced initially and most intensely during the first semester of study, followed by rapid adjustment. The following quotation illustrates Zhou's early experiences: "I just come to Canada, I need time to familiar with such as English. So in my first class it's a little difficult to understand all the professor said, so I'm afraid and I'm worried about the whole course." For Zhang, focusing on reading improved comprehension: "You know, when I first come here, my listening ability is very poor. So I almost can't understand anything in the class. So main method I learn is by reading.”

With the passage of time, participants' abilities with and perceptions of language changed. For Song, "Ya, at the beginning I think it's very hard but now it's easier." Many participants noted that their sense of crisis around language skills diminished after half a year or more in this academic setting. Though language continued to play an important role, they turned their eyes to other matters such as contact with local people, finishing the degree and more complex academic tasks. Although language remained a barrier, it became the medium through which other challenges had to be addressed, rather than the central challenge. As Zhou said, 'English skill is not the only thing for study, it's just for 
show you the ideas.” This statement reflects an understanding of English not as a grammatical construction, but as a tool for communicating and for displaying one's personality and potential. Shifting perspectives on language skills appeared to relate to a changing understanding of the linguistic demands upon them, and to the varying demands of different contexts, for example, the shift from functional English to the more complex requirements of academic English discourse.

In discussing his language in Canada, Zhang stated, "Professor, so they think I have no problem, but I have." His increasing facility with everyday English masked his ongoing difficulties with academic English, so that professors overestimated his capacity to manage and excel in academic work. There were specific academic tasks that participants found problematic, and most of them related to language; specifically, presentations, group work, and in-class discussions.

\section{Specific academic tasks}

Oral presentations, class discussions and group projects were consistently identified as difficult components of Canadian classroom expectations. Some students struggled, especially initially, with these unfamiliar academic tasks. As Dong said, "I am not confident with presentation at the beginning because I never gave presentation in China ... especially in my first course ... that was nervous. But after several presentations, I feel okay." For Zhang, "the easiest for me is assignment ... the writing part. The difficult one is presentation and discussion with others. That need express my ideas clearly and fluently so this is difficult for me.” When probed further about presentations, Zhang said that if he had no language problem, he would be confident any time. For Ming, pronunciation was his main concern when presenting: "How to express it I have to be careful... how to prepare to speak a line. I have to be careful about my pronunciation.” Another participant, Yang, identified presentations as a big difference because "in China, there are no presentations for courses.” Regarding class discussions, Dong stated, "I'm totally no idea, what should I do in a discussion." Dong is unable to enter the classroom discussion discourses because he is unsure of "what" he should say and "how" he should say it. Effectively excluded from the discourse of classroom discussions, he continues to assume personal responsibility.

Assuming personal responsibility

One recurring theme was participants' tendency to accept personal responsibility in situations where they encountered difficulties that resulted in their being excluded from discourses. They held the belief that it was the student's responsibility to conduct herself or himself appropriately in the academic realm, which includes promoting positive relationships and excelling academically. These beliefs shaped the way that students perceived situations within the 
Canadian university context that placed them on the margins. One illustrative narrative goes as follows:

For the first year I have some courses together with undergraduate students, most of them are Canadians, and when we talked something.... I just feel like I don't know what I should talk about. I can understand them, but I can't find a topic. I just feel that there is nothing in common, and wooo, I just smiling and smiling, I don't know what the hell I should say. (Jiang)

In this passage, Jiang clearly perceives that it is up to the outsider to find an entry point, to find a topic, not up to the insiders to make room. Her subsequent positioning of the story clearly reflects this:

Well, if they don't like you that's okay as long as you like yourself. So it's the same thing, well, you can think yourself as an insider, what the hell to do with other think you are an outsider. It doesn't matter.

She attempts to resolve the problem internally, to change her own response to it, rather than to challenge the situation or to defend herself. Another participant, Zhang, explained, “They tried to give me help but you know it's not depend on their help but on my language. If my language is improved, they can push me to involve. But my language keep here in this.” Again, we see Zhang taking full responsibility for his inability to participate in spoken English discourse.

Another participant described her experiences of social exclusion in the Canadian classroom setting:

In China, we don't have group project. [Here], we communicate, but we can only communicate just for the project, not others.... I don't know how to express that. ... Maybe more negative ... (Yang)

Yang's meaning is that the only communication that occurs is workfocused and nothing beyond that, i.e., no social interactions. Closer analysis reveals Yang's resistance to this situation through the use of "can only", "just" and "negative." She is hedging in her description of this experience, perhaps to be polite in light of the audience that includes a Canadian interviewer. Though she senses that socializing with her group is not an option, she still maintains an ethical standard that requires her to work hard to improve herself and to not blame others for her problems.

There are other subtle indications of difficulty in speaking to Canadian students in general. Ming, for example, said he spoke with two classmates: one from India and one from Brazil. When asked why he did not communicate with Canadians, he said, "communication with a Canadian is a little more difficult because it's too hard. But with people from other country, a little easier” (Ming). 
At another point in the interview, Ming states his main challenges as, "The language, and uh, the culture, and communicating with ... other people.” The hesitation and reluctance to identify specifically the "other people" intimate Ming's indirect mode of discourse in this interview setting.

In Zhang's case, he found it easier when a group of international students went to a professor's house "because the situation. There are more foreigners so they can consider foreigners' condition.” Regarding involvement with Canadian students, Zhang states, "There is not this kind of activities by far in the two years I have been here." The use of "by far" suggests that socializing with Canadians simply does not happen.

According to the descriptions of the participants, the academic culture at the university is partially impermeable to them, as indicated in Table 1.

\begin{tabular}{|l|l|}
\hline \multicolumn{1}{|c|}{ Permeable aspects } & \multicolumn{1}{c|}{ Impermeable aspects } \\
\hline * Written work / assignments & * In-class discussions \\
* Lab work & * Oral presentations \\
$*$ Tests & $*$ Group work / projects \\
$*$ Linguistic ability (reading) & $*$ Linguistic ability (listening, \\
& pronunciation) \\
& * Communicate with local people \\
& $*$ Other more complex academic tasks \\
\hline
\end{tabular}

Table 1: Permeable and impermeable aspects of the culture for participants

Insider-Outsider Status

One interview question asked specifically where participants placed themselves on a spectrum from insider to outsider. Participants shared experiences of being both insiders and outsiders in their academic departments. While conducting analysis in monocultural dyads, the Canadian dyad noted that, when describing experiences of being on the periphery, no students attributed exclusion to bias or racial issues. Through negotiation, and particularly the Chinese researchers' insights, it became clear that culturally influenced moral imperatives were at work in participants' sense making of their experiences in Canada. The Chinese dyad acknowledged that the presence of Canadian interviewers may have affected willingness to speak more directly about such matters; however, they argued that participants' stories should be taken at face value in light of the culturally embedded conception of "three good student" (Ying, 2005). This refers to the three main categories that make up a good student in China: being obedient, being modest and getting high academic grades. In essence, by evaluating their successes and failures based on their own personal resources and abilities to respond to challenges in the Canadian context, students might both strive for self- 
improvement and avoid acknowledging real and persistent barriers within the Canadian academic context.

Yang placed herself near "outsider" because she did not know the other students and because her undergraduate degree was not in the same field as her graduate work. Most other participants placed themselves near the middle. Zhou, who had been in Canada eight months, positioned herself half-way between insider and outsider. When asked who or what made her feel more like an insider she identified "some Chinese people" and when asked who or what made her feel like an outsider, her one-word reply was, "English.” Song, in her first year of study, also said she felt right in the middle. She socialized and worked mainly with Chinese students so in a sense, she felt like she was still in China. On the other hand, she took courses that gave her a Canadian perspective so this is why she placed herself in the middle: insider with respect to Chinese involvement and outside with respect to Canadian involvement. Dong, $1 \frac{1}{2}$ years into his Masters, placed himself in the middle as well, stating that he was not a total insider because of the language problem; that it would take at least another year to become an insider. Huang said her positioning was dependent on the courses she took. For instance, in her course with a young female Chinese professor, Huang said she felt like an insider because, "It's easy for us to ... communicate.” In another course taught by a professor of a different nationality, she said she felt more like an outsider. Zhang felt like an insider academically because he had strong background knowledge but socially, he felt like an outsider. For example, when he went to a party where they were drinking beer, he was confused and could not understand what they are talking about. "So I feel embarrassed so I don't like to be together with them. So at last, if they ask me, 'let's go to the bar', I don't like because they can talking and laughing with each other. I am like an idiot. (laugh) Idiot. Keep silent.” Zhang thus articulates "language-in-use" (Gee, 2005) as the major determinant of his insider-outsider status. Thus, most participants placed themselves in the middle of the insider-outsider spectrum. Their reasons for feeling like an outsider were generally due to communication and/or informal social experiences, or the lack of participation therein.

Two participants placed themselves as insiders. Ming, in Canada almost two years, said that he felt almost like a total insider. At first, he felt like an outsider because he "knew nothing", but now that he knew his classmates, his professors, and the work they were doing, he felt more like an insider. The one area where he felt like an outsider was in informal discourse with professors. "Some students when they want to talk to professor they simply go to the door and say, 'Hi Doctor' but I cannot. I have to make appointment. But some just go to the door and they open it and they can talk." This deals with the "ways" of communicating informally. When asked where she placed herself on a continuum from complete insider to complete outsider in the academic culture of her 
department in this, her second year, Jiang said, “complete insider." In her department, all but one of the students in her program are Chinese and most of the professors are Asian so she has no trouble understanding and communicating. While she feels like an insider, this is not entirely satisfactory to Jiang because, "This is nothing related to what I expected of what a Canadian study should be like. I thought it should be colourful and we talking in English always." In contrast, during her first year, when she had Canadian classmates, she was "definitely not a total insider." She had nothing in common with them and so could not find a topic to allow her to enter the discourse. "I just felt it weird, I think the most important reason is different cultural background and the.... English community." Jiang's explanation is unique in that she does not assume complete responsibility for outsider status but points to the "English community." Although it was evident that participants had little experience in socializing with Canadian classmates, they did have at least one social connection, Canadian or Chinese, who helped them navigate the Canadian academic culture. The Discussion section will include the roles of these "cultural mediators" as we follow the paths of three participants' entry into the Canadian academy.

\section{Discussion}

Negotiating Entry into the Academic Culture: Personal Identity Resources

Almost invariably, participants described their first learning experiences in Canada in terms of confusion. In this new environment, there is much that does not make sense, that is difficult to interpret because the individual's existing construction of identity is at odds with it, or because of culturally constructed boundaries to entry. Though research (Koehne, 2004) has aimed at deconstructing such taken-for-granted "knowledge", traditional cultural constructions of international students persist (Spencer-Rogers, 2001; Spencer-Rogers \& McGovern, 2002), placing international learners at a disadvantage. International students must find ways to work around both the positioning and the unfamiliar academic practices that marginalize them and their knowledge. As Huang argued in describing her initial experiences of the academic challenges of negotiating this alien academic setting, "I have no expectation [of good grades]. The system is fixed. The important thing is to just get used to it." Within such dominant culture constructions, however, there are sometimes spaces that are more permeable. Often, these spaces are narrow: these narratives suggest that identity reconstruction is an aspect of how students navigate points of entry.

As Hall (1996) has argued, the process of identity formation, of telling your story to yourself in a particular way, of taking up particular aspects of your own story, while leaving others aside, is one of the ways that individuals produce themselves to negotiate the diverse cultural spaces they traverse. In Hall's terms, there are ways in which others tell your story, which may position you in certain 
ways in society, and ways in which you tell your own story. Sometimes your story of yourself flatly contradicts the dominant culture story: often, though, you may tell your story in ways that offer you more room to manoeuvre within the spaces into which dominant culture has placed you. To understand the ways in which these students navigate their new field of practice, it is important to understand their reconstruction and re-deployment of identity resources.

When confronted with an impermeable aspect of the culture, participants generally depended on themselves to figure a way out, taking up resources from their repertoires related to specific aspects of their identities, and relinquishing those involved in other social identities, based on the aspects of the culture that were visible, understandable and permeable. By focusing on specific resources or strengths and abilities, participants formulated or reformulated identities that were recognizable to members of the dominant culture. It also reflected the aspects of the academic culture here that were recognizable to each of them. Through this identity, even aspects of the culture that previously seemed impenetrable appeared to become more accessible.

\section{Dong's path of entry: "Work-based" identity}

Dong's adoption of an identity narrowly focused on resources related to his diligence provides a clear example of this process. Although his narrative identity in China tended to highlight social interactions and friendships, his identity in Canada negates that identity. He views himself as "not a good talker" in either English or Mandarin, and as not really a funny guy. This contradiction appears to be connected to the resources he has identified as supporting his entry into the academic culture as he experiences it here.

For Dong, classroom discussions proved to be a relatively impermeable aspect of Canadian academic culture. Many studies have described the cultural barriers Chinese students experience in discussion: the cultural value placed on participation through attentive silence (Liu, 2002), the differences in attitudes towards the use of text (Durkin, 2004), the cultural inappropriateness of openly criticizing authority figures (Durkin, 2004), and concern over language inadequacy (Liu, 2002). Dong describes his experiences of discussion in the following way:

I never went through this discussion in China. I'm totally no idea, what should I do in a discussion. No one told me, and also I don't know... So maybe here, Canadian students they went through many, many discussions. They know what they should do...They give lots of opinions... I really don't know what - how- comment a paper like that.

Here, Dong appears to be seeking among a lexicon of roles and practices for the ones appropriate to the context. He describes his reactions to his Canadian peers' discussion practice in terms that indicate his sense that he is failing to 
perform appropriately: "I should, I really should... because in discussion, you really should talk something, right? They did a really good job. What should I do?”

What is appropriate? What is the right role? As Gee (1990) argues: in socially situated language use one must simultaneously say the "right" thing, do the "right" thing, and in the saying and doing express the "right" beliefs, values and attitudes.

The primary focus of Dong's narrative and identity within his academic community is lab work. He is clear about the tasks, and clear about his role in this context. In Gee's (2005) terms, Dong is engaged here in recognition work: in making who he is and what he is doing visible in a context in which his personal resources are most suited to the demands and where he has reason to believe that others in the discourse view his actions as recognizably part of the discourse. Dong's nearly exclusive use of the word "boss" to describe his advisor indicates his construction of the lab work as professional work, rather than as learning or academic practice. His focus on research as an alternative to his former medical career perhaps informs this construction of his practices here as work rather than study.

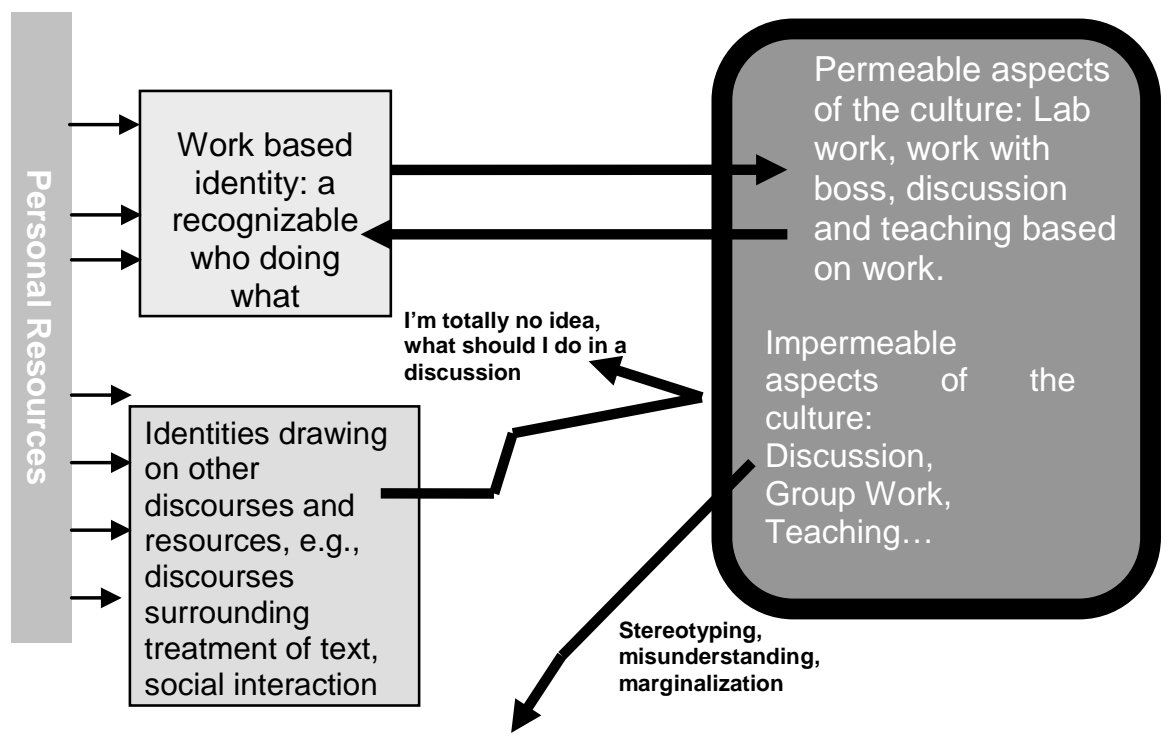

Dong's path of entry into the academic culture: Work-based identity

For Dong, practices related to 'the work' are key identity resources that open up less permeable aspects of the academic culture. Work provides him with the authority to speak from knowledge that he trusts in a way that he knows others 
will believe. When it comes to articles related to work he has done himself, critique and discussion are "totally different" from other situations: "you will get a very deep impression. You know, what's good and not good of these techniques." He is able to formulate a "who" doing "what" that functions in the context, and that is also recognizable to members of the dominant discourse.

\section{Jiang's path of entry: "Strategist" identity}

Jiang carries on her narrative and identity in the Canadian academic setting as a strategist. She sets her goals and then works to achieve them, logically, and chronologically. Fourteen times during the interview, she begins her responses with, "First of all, ...". This strategic approach to academics has allowed her to be successful in China, where she completed two undergraduate majors (72 courses rather than the usual 40) in four years and studied the job market in order to determine what certificate courses to pursue. This personal resource of strategizing follows her to Canada, where she devises a step-by-step plan that involves establishing herself academically during her first year and then, attempting to enter Canadian society.

First of all, I said okay, you must concentrate on your study, and after the first semester, I seemed that I established my academic field a little bit, and the next thing I thought, okay, for the two goals that you want to go Canada to study, one to have a major, to have a master degree, another is to improve your English, ... so I moved out of the house that I already lived for last year and I looked for a Canadian landlord and actually now I'm living with her.

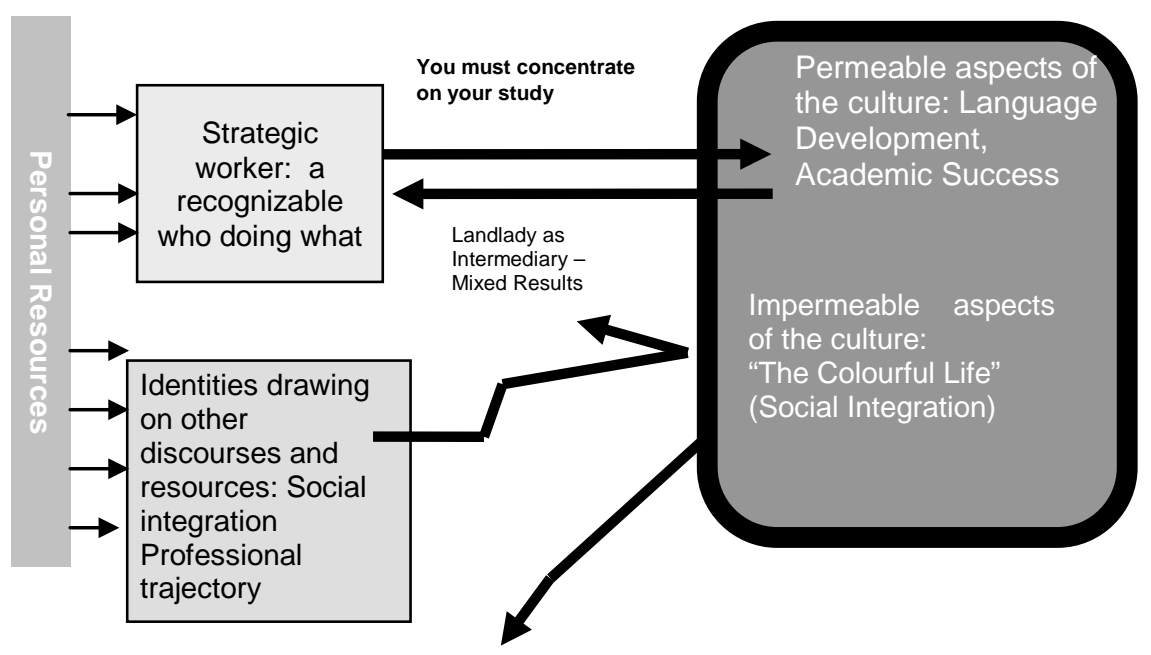

Jiang’s path of entry into the academic culture: “Strategist” identity 
In Jiang's first year, she was unable to speak to Canadian students because, she said, she did not know "what the hell" to talk about. Since her goal that year was not speaking English but establishing herself academically, she "stayed in the library." When asked what advice she would give to another Chinese graduate student coming to Canada, she says, "first you must have specific objective way" and "you can't make a decision in a rush, because studying abroad is an investment for your parents."

This strategy allowed Jiang to have regular contact with her landlady, and a by-product of her living with this lady was that she would be regularly indoctrinated with "western" and "Christian" beliefs. Regardless, beyond her landlady, Jiang had no strategy to place her effectively in the discourses of Canadian society. She felt she "lost a lot of things" in her first year when she spent hours in the library to understand the content of her new major. She thought academic life in Canada "should be colourful and we talking in English always." Though Jiang is succeeding academically in Canadian graduate school, where she speaks mainly Mandarin, the one area that remains impenetrable to Jiang is "a colourful life." Speaking English at school is a big part of achieving this "colourful life" but Jiang has no strategy for conversational discourse beyond her landlady.

\section{Huang's path of entry: "Performance" identity}

Huang's identity is a performer. She has decided, with the help of her boyfriend, that she is not suited to the academic life. Thus, she rejuvenates her identity as a performer and gains access to the Canadian academic culture in this way.

Huang identified her academic life back in China as a successful and active path. She had a strong social network in China due to her skills in dancing and performance. Given that confidence and experience, she entered her expected department and worked hard to achieve academic advancement in Canada. She was passionate about her winning scholarships, which meant a credit to her diligence and independence from her parents. She often referred to her boyfriend in the interview, who had been in the same department but ahead of her in the program. In addition to assisting Huang's early adjustment to Canada, both academically and socially, it appeared he also gave advice on her future path. She has decided to stay in Canada with her boyfriend after graduation, but despite a successful academic career in China, now says:

I'm not suitable for [my field of study] .. So my boyfriend said. I'm suitable to do some ... well, performance things, or maybe do some business, or something like that .. I'm not suitable to sit here, and study. (Huang) 


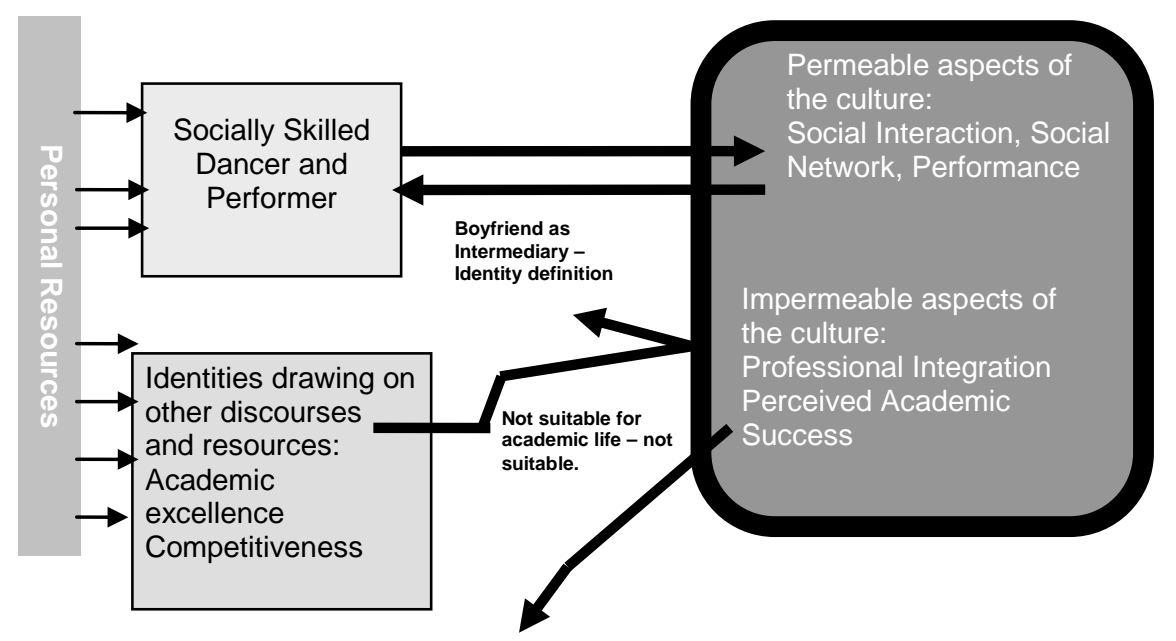

Huang's path of entry into the academic culture: "Performance” identity

Paradoxically, her descriptions of her academic achievement in the university were not the same as what she or her boyfriend claimed. Due to her extrovert personality and talent as a dancer, she established a good relationship with her teachers and peers. She not only helped her peers in the completion of assignments, but also frequently invited them home. Her participation in the academic culture is comparatively colourful and permeable. However, as a major part in her life, her boyfriend had a dominant influence on her attitudes towards academic life. She accepted what her boyfriend said, and firmly believed it was the truth. Despite clear and consistent evidence of her academic strengths in her academic life before arriving in Canada, the influence of this cultural mediator has been powerful in shaping her current self-image and goals. Her reliance on her boyfriend limited her ability to see her own successful adaptation into the academic culture.

\section{Conclusion}

In conclusion, while Chinese graduate students perceive the differences between the Chinese and Canadian education systems, they gradually negotiate and enter into this new academic culture in respective ways. Even though they find the graduate program is somewhat impermeable, they depend to a great deal on their existing home cultures and learning experiences. In many participants' narratives, we observed that the individuals' principles, their ideas, for example, of striving for self-perfection, or setting goals and achieving them step by step, remained the same. What changed was the content of the goals: the striving attached itself to 
different definitions in the new context. In this way, the cultural foundations of the ways individuals identify and approach problems may continue to exert a powerful influence in new contexts.

Meanwhile, participants made use of a variety of personal and external resources in entering the academic culture. But not all resources were equally accessible or effective for all students. Some participants established a wide range of social networks, whereas others relied heavily on academic study, under the constraint of limited personal relations. Management of cultural difference is very individual. The resources people take up to negotiate this process, and their perception of the goals of the process, cannot be generalized into one ideal approach to negotiating new cultural spaces. Students took up the resources that could be applied to the parts of the culture that were visible and understandable to them. Responses they met with within the culture tended to confirm the resources that they continued to utilize and value within this context, and limit their use of resources which appeared not to be recognizable by people in the culture whose opinions they valued. It would be valuable to identify the resources commonly visible, and those visible only to one party, as an alternative to deficit-based approaches to studies of international students, and to consider what might make resources recognizable, accessible and effective both for international students and for host culture participants in the academy.

\section{References}

Clandinin, D.J., \& Connelly, F.M. (2000). Narrative inquiry: Experience and story in qualitative research. San Francisco: Jossey Bass Publishers.

Connelly, F.M., \& Clandinin, D.J. (1990). Stories of experience and narrative inquiry. Educational Researcher, 19 (5), 2-14.

Cooke, P. (1995, February). How sojourner students cope: When perceptions of teachers don' $t$ match expectations. Paper presented at the Annual Meeting of the Western States Communication Association (Portland, OR).

Creswell, J. W. (2003). Educational research: planning, conducting, and evaluating quantitative and qualitative research $\left(2^{\text {nd }}\right.$ ed.). NJ: Pearson Merrill Prentice Hall.

Dee, J., \& Henkin, A. (1999). Challenges to adjustment to college life in the United States: Experiences of Korean students. International Education, 29(1), 54-70.

Durkin, K. (2004). Challenges Chinese Students Face in Adapting to Academic Expectations and Teaching/learning Styles of U.K. Masters Courses, and How Cross Cultural Understanding and Adequate Support Might Aid them to Adapt. Retrieved May 3, 2003 from http://www2.britishcouncil.org/zh/china-educationscholarships-china-studies-grant-awardlist-kathydurkin.pdf 
Erwin, T., \& Coleman, P. (1998). The influence of intercultural experiences and second language proficiency on college students' cross-cultural adaptability. International Education, 28(1), 5-25.

Fairclough, N. (1993). Discourse and social change. Cambridge, UK: Polity Press.

Fairclough, N. (1995). Critical discourse analysis: The critical study of language. New York: Longman.

Fairclough, N., \& Wodak, R. (1997). 'Critical discourse analysis' in T. Van Dijk (Ed.), Discourse as social interaction (pp. 258-284.) London: Sage .

Feiz, Y. (1995). A study of problems faced by post-graduate visa students at the University of Toronto and York University. Unpublished doctoral dissertation, University of Toronto, Toronto, Canada.

Gee, J. P. (1999). An introduction to discourse analysis: Theory and method. New York: Routledge.

Gee, J. P. (2005). An Introduction to Discourse Analysis: Theory and Method (2 ${ }^{\text {nd }}$. Ed.). London: Routledge.

Grayson, J. P., \& Stowe, S. (2005). Language problems of international and domestic ESL Students at UBC, York, McGill and Dalhousie, and academic achievement. Presented to the 2005 Annual Meetings of the Canadian Society for the Study of Education, London Ontario.

Hall, S. (1996). Politics of Identity. In T. Ranger, Y. Samad, \& O. Stuart (Eds.) Culture, Identity and Politics (pp. 129-135). London: Anebury-Ashgate.

Kilbride, K. M., \& D'Arcangelo, L. (2002). Meeting immigrant community college students' needs on one greater Toronto area college campus. The Canadian Journal of Higher Education, 32(2), 1-26.

Koehne, N. (2004).Positioning international education and international students: Muliple discourses and discursive practices. Paper presented at the AARE conference, Melbourne, Australia, November.

Ku, C., Lee, C., Pan, C., Tao, Y., Wang, Z., Cornell, R., Ku, H. (2001, November). East meets west times 2: Impact of cultural changes at two universities on Asian students. Annual Proceedings of Selected Research and Development (and) Practice Papers Presented at the National Convention of the Association for Educational Communications and Technology. Atlanta, GA.

Liu, J. (2002). Negotiating silence in American classrooms: Three Chinese cases. Language and intercultural communication. 2(1), 37-54.

McGregor, S. (2002). Critical discourse analysis: A primer. Kappa Omicron Nu FORUM, 15(1). Retrieved January 24, 2004, from http://www.kon.org/archives/forum/151/mcgregorcda.html

Razack, S. (1995). The perils of talking about culture: Schooling research on South and East Asian students. Race, Gender and Class, 2(3), 67-82.

Ristock, J. L., \& Pennell, J. (1996). Community research as empowerment: Feminist links, postmodern interruptions. Toronto, Canada: Oxford University Press

Sheh, S. (1994). Adjustment of Hong Kong students at the University of Alberta. Unpublished doctoral dissertation, University of Alberta, Edmonton, Canada.

Solomon, R.P. (1997). Reconstructing teacher education for educational equity and diversity. Caribbean Journal of Education, 19(1), 36-49.

Solomon, R.P. (1998, April). Exploring cross-race dyad partnerships in learning to teach. A paper presented at the American Educational Research Association (AERA) Annual Meeting, San Diego. 
Solomon, R.P., \& Levine-Rasky, C. (2003). Teaching for equity and diversity: Research to practice. Toronto: Canadian Scholars' Press.

Spencer-Rogers, J. (2001). Consensual and individual stereotypic beliefs about international students among American host nationals. International Journal of Intercultural Relations, 25, 639-657.

Spencer-Rogers, J. \& McGovern, T. (2002). Attitudes towards the culturally different: The role of intercultural communication barriers, affective responses, consensual stereotypes, and perceived threat. International Journal of Intercultural Relations, 26(6), 606-631.

Tanaka, G. (2002). Higher education's self-reflexive turn: Toward an intercultural theory of student development. The Journal of Higher Education, 73(2), 263-296.

Tsai, J. H. (2006). Xenophobia, Ethnic Community, and Immigrant Youths' Friendship Network Formation. Adolescence, 41, 285-98.

Welch, N. (1993). Resisting the faith: Conversion, resistance, and the training of teachers. College English, 55(4), 387-401.

Williams, M. T., \& Garcia, G. (2005). Crossing academic cultures: A rubric for students and teachers. Journal of Basic Writing, 24(1), 93-119.

Ying, W. (2005, March 24). "Three-good” student system under revision. China Daily. Retrieved May 6, 2005, from http://www.chinadaily.com.cn/english/doc/200503/24/content_427648.htm

Dr. Sheila Windle (swindle@uwindsor.ca) is a post-doctoral fellow at the University of Windsor, Faculty of Education. Her interests lie in socio-cultural aspects of additional language learning, religious and cultural pluralism in the Canadian classroom context, and culturally inclusive pedagogy in Health and Physical Education.

Beverley Hamilton (Beverley@uwindsor.ca) completed her M.Ed. in Education at the University of Windsor. She is currently Assistant to the Vice-Provost at the University's Centre for Teaching and Learning.

Min Zeng ( zeng3@uwindsor.ca) as a teacher of English in China. She completed her Masters of Education at the University of Windsor in 2004 and is now a doctoral candidate. Her research interests include cultural studies and second language teaching and learning.

Xiaodong Yang (xy@ualberta.ca) was an English teacher in China. He completed his M. Ed. at the University of Windsor in 2005 and is now a Ph.D. provisionary candidate at the University of Alberta. His research interests include: cultural studies, critical discourse analysis, curriculum studies, teaching and learning, hermeneutics, globalization, Internet, and teaching and learning. Presently, he is investigating the "cultural meaning of plagiarism". 